\title{
The Role of Photoperiodism in Alpine Plant Development
}

\author{
Franziska Keller \\ Department of Geosciences, Geography, \\ Pérolles, CH-1700 Fribourg, Switzerland. \\ Franziska.Keller@unifr.ch

\section{Christian Körner}

Institute of Botany, Schönbeinstrasse 6, CH-4056 Basel, Switzerland.

\begin{abstract}
Is alpine plant development in spring controlled by photoperiod irrespective of actual temperatures at the time following snowmelt? We investigated phenological responses to day length and temperature in 33 high-elevation species of the Central Alps (2600-3200 m a.s.l.), Austria. Plants were collected in the field in August, potted, and overwintered in a freezer at $-1^{\circ} \mathrm{C}$. Released from dormancy, plants experienced various photoperiods $(12,14.5,15$, and $16 \mathrm{~h})$ and two temperature regimes $\left(6 / 11^{\circ} \mathrm{C}\right.$ and $\left.8 / 18^{\circ} \mathrm{C}\right)$. Day length was extended with tungsten lamps, which do not contribute a significant dose of photosynthetically active photon flux density but provide a day-length signal. Only 23 species produced sufficient flowers to be included in the analysis. Flowering (yes or no) was sensitive to photoperiod in $54 \%$ of the species. Surprisingly, only $24 \%$ of the species showed temperature sensitivity at longer photoperiods, whereas at shorter photoperiods, $65 \%$ of the species were sensitive to an increase in temperature. The number of days between thawing of soil and flowering is sensitive to photoperiod in $46 \%$ of the species. Cerastium uniflorum, Elyna myosuroides, Saxifraga oppositifolia, Saxifraga seguieri, and Ranunculus glacialis are insensitive to both photoperiod and temperature and thus flower as soon as released from the snow irrespective of co-occurring light and temperature conditions. Specific leaf area and the duration of leafing were responsive to photoperiod and temperature in forbs but not in grasses. These results suggest that about half of the tested alpine species are sensitive to photoperiod and may not be able to fully utilize periods of earlier snowmelt.
\end{abstract}

\section{Introduction}

In humid extratropical areas, photoperiod and temperature are the main environmental factors controlling the rhythm of growth and flowering in plants (Bernier and Sachs, 1981, Heide et al., 1990). In periodically cold climates, photoperiod sensitivity of plants (photoperiodism) assures that development does not follow thermal peculiarities, e.g., warm spells too early in the season, which would be fatal for active plant tissue (Körner, 1999). Photoperiodic control becomes less strict as spring progresses, with thermal conditions becoming more influential. Once a specific photoperiod threshold has been surpassed, the onset of spring growth and flowering in photoperiod-sensitive plants depends on snow cover and temperature only. Photoperiodism not only protects plants from risky sprouting before the end of the period of severe frost but also results in a certain degree of synchrony of flowering among individuals within populations, which is essential for cross-pollination (Heide, 1985) and is commonly under strong genotypic control (no "acclimation"). Transfer of plants to a different photoperiod often creates a major disturbance of development (Prock and Körner, 1996). The projected global warming of $1.4-5.8 \mathrm{~K}$ by the end of this century (IPCC, 2001) may cause an even earlier onset of the growing period and therefore shorten the photoperiod at which species emerge from melting snow, unless increased snowfall and snowpack counteract these trends (Beniston, 2000). Myneni et al. (1997) and Menzel and Fabian (1999) have shown that mean length of the growing season in the Northern Hemisphere temperate zone has been extended on average by $10.8 \mathrm{~d}$ from 1959 to 1993 as a result of global warming. They found that spring events, such as leaf expansion, shoot growth in May, and flowering, have advanced by $6 \mathrm{~d}$ over the last $30 \mathrm{yr}$. In mountainous areas, this warming and potential earlier release from snow may become much more dramatic, but it will not necessarily be advantageous to plants (Körner, 1999). Upward species migration in mountains has already been observed by several authors (BraunBlanquet, 1957; Hofer, 1992; Grabherr et al., 1994; Gottfried et al., 1998) and has been attributed to climatic warming in the 20th century.

The focus of this study is on mountain plant species because it is estimated that they may be particularly sensitive to climatic change given their existence close to the thermal limits of plant life (e.g., Barry, 1992; Körner, 1999). At high altitudes, physical factors such as season length and snowpack are of greater significance for plant success than biotic interactions (Heide, 1985; Larcher, 1994). Therefore, depending on snow cover and snow distribution, changes may be much more pronounced at high than at low elevations. Heide (1989) and Heide et al. (1990) showed that subarctic Phleum alpinum and high arctic Cerastium regelii have a dual photoperiodic induction requirement for flowering: a primary short-day reaction for initiation of primordial flower buds (in autumn), i.e., the induction of reproductive tissue formation, and a secondary long-day induction for flowering (spring and summer) that can be modified by temperature. Alpine plants have similar physiological controls as arctic plant species. This study addresses the second induction: the flowering process and associated vegetative expansion in spring.

It is not known to what extent plants in mountain regions are photoperiod sensitive, nor do we know how photoperiodism interacts with temperatures in these environments. Some species may sprout and flower irrespective of date of release, and others may not make any use of earlier snowmelt and the added season length. In fact, they may show increased respiratory losses due to warmer temperatures. In the long run, such differential responses to climatic change would cause rearrangements of plant communities and change species abundance. Interaction of photoperiodism with temperature is of interest because high temperatures can operate as a long-day surrogate (Heide, 1989). It is unlikely that warming will be so dramatic as to compensate for the 
TABLE 1

Plant species ${ }^{\mathrm{a}}$, taxonomic abbreviations, altitude of origin, photoperiod $(P P)$ at the beginning, and peak of flowering according to Bahn and Körner (1987)

\begin{tabular}{|c|c|c|c|c|}
\hline Species $^{\mathrm{a}}$ & $\begin{array}{c}\text { Taxonomic } \\
\text { abbreviation }\end{array}$ & $\begin{array}{l}\text { Altitude } \\
(\mathrm{m})\end{array}$ & $\begin{array}{c}\text { earliest } \\
\text { flowering } \mathrm{PP}^{\mathrm{b}}\end{array}$ & $\begin{array}{c}\text { peak } \\
\text { flowering } \mathrm{PP}^{\mathrm{b}}\end{array}$ \\
\hline Agrostis rupestris & Agr rup & 2950 & $15: 13$ & $14: 38$ \\
\hline Androsacea alpina & And alp & 3020 & $15: 53$ & $15: 46$ \\
\hline Avenochloa versicolor & Ave ver & 2950 & - & - \\
\hline Carex curvula & Car cur & 2620 & $15: 49$ & $15: 12$ \\
\hline Cerastium uniflorum & Cer uni & 3050 & $15: 55$ & $15: 24$ \\
\hline Elyna myosuroides & Ely myo & 2950 & - & - \\
\hline Erigeron uniflorum & Eri uni & 3100 & $15: 21$ & $14: 52$ \\
\hline Festuca af. intercedens & Fes af int & & - & - \\
\hline Gentiana bavarica & Gen bav & 3020 & $15: 55$ & $15: 38$ \\
\hline Geum montanum & Geu mon & 2950 & $15: 55$ & $15: 34$ \\
\hline Geum reptans & Geu rep & 2650 & $15: 56$ & $15: 47$ \\
\hline Gnaphalium supium & Gna sup & 2650 & $15: 22$ & $15: 01$ \\
\hline Leucanthemopsis alpina & Leu alp & 2650 & $15: 54$ & $15: 35$ \\
\hline Linaria alpha & Lin alp & 2820 & $15: 55$ & $15: 34$ \\
\hline Luzula spicata & Luz spi & 3050 & - & $15: 39$ \\
\hline Minuartia sedoides & Min sed & 2620 & $15: 39$ & $15: 08$ \\
\hline Oreochloa disticha & Ore dis & 3050 & $15: 56$ & $15: 47$ \\
\hline Oxyria digyna & Oxy dig & 2650 & $15: 53$ & $15: 23$ \\
\hline Phyteuma hemisphaericum & Phy hem & 2950 & $15: 10$ & $14: 46$ \\
\hline Poa alpina & Poa alp & 2820 & - & $14: 40$ \\
\hline Poa laxa & Poa lax & 3050 & - & $14: 51$ \\
\hline Potentilla frigida & Pot fri & 3100 & - & - \\
\hline Primula glutinosa & Priglu & 3050 & $15: 31$ & $15: 45$ \\
\hline Ranunculus glacialis & Ran gla & 3020 & $15: 18$ & $15: 32$ \\
\hline Salix herbacea & Sal her & 2650 & - & $15: 22$ \\
\hline Saxifraga bryoides & Sax bry & 3050 & $15: 27$ & $14: 54$ \\
\hline Saxifraga oppositifolia & Sax opp & 3100 & - & $15: 46$ \\
\hline Saxifraga seguieri & Sax seg & 2650 & - & - \\
\hline Sedum alphestre & Sed alp & 2610 & $15: 30$ & $15: 00$ \\
\hline Sempervivum montanum & Sem mon & 2950 & $15: 07$ & $14: 59$ \\
\hline Sibbaldia procumbens & Sib pro & 2650 & - & - \\
\hline Veronica alpina & Ver alp & 2620 & $14: 54$ & $14: 29$ \\
\hline Veronica bellioides & Ver bel & 2950 & $15: 37$ & $15: 13$ \\
\hline
\end{tabular}

${ }^{a}$ Nomenclature follows Ehrendorfer (1973).

b averages according to Bahn and Körner (1987).

photoperiod effects of earlier snowmelt, but it may be useful to know to what extent temperature can interfere with photoperiodism.

In this study, we used four photoperiods and two temperature regimes to examine dates of flower appearance, leafing, and specific leaf area. The null hypothesis is that alpine species are not photoperiod sensitive with respect to the onset of flowering but adjust their phenology to the release from snow and to temperature. For taxa that are photoperiod sensitive, a second hypothesis is that warm temperatures can overcome the long-day requirements. Since significant influences of photoperiod on leafing and leaf quality have been documented for arctic plants, we expected similar trends in alpine plants; hence, our third hypothesis is that long photoperiods stimulate leaf expansion and increase the leaf area produced per unit of leaf mass.

\section{Methods}

\section{EXPERIMENTAL PLANTS AND GROWTH CONDITIONS}

Forty individuals each of 33 high alpine species were excavated at altitudes between 2600 and $3200 \mathrm{~m}$ a.s.l. at Mount Schrankogel, Tyrol, in the Eastern Central Alps of Austria $\left(11^{\circ} 05^{\prime} 58^{\prime \prime} \mathrm{E}, 47^{\circ} 02^{\prime} 41^{\prime \prime} \mathrm{N}\right) 2$ to $3 \mathrm{wk}$ before the end of the growing season in August 1999 (Table 1). Individuals were collected from different locations to avoid biased sampling. The entire plant with most of its roots was excavated, plus some native soil attached to the roots. All remaining flowers were removed.

The plants were transported to the Basel Botanical Institute in cool boxes and were potted in soil from the field site diluted by washed siliceous sand. For practical reasons, we potted 3 independent individuals of each species to one 0.3 -liter plastic container $(7 \mathrm{~cm}$ long $\times$ $7 \mathrm{~cm}$ wide $\times 11 \mathrm{~cm}$ high). Two pots per species (i.e., 6 individuals) were used for each treatment combination, which yielded a total of 12 pots and 36 individuals per species for the whole experiment.

For the rest of the 1999 growing season, all plants were maintained in daylight growth cabinets at a $14 / 10^{\circ} \mathrm{C}$ (day/night) temperature regime, with supplemental light from 8 A.M. to 5 P.M. At the beginning of November, when plants were senesced, they were transferred to a freezer set to $-1^{\circ} \mathrm{C}$ for $3 \mathrm{mo}$. The following season was initiated artificially under controlled photoperiod. The plants were allowed to thaw under a cover of ice pellets renewed twice a day during the first $3 \mathrm{~d}$ after release from the freezer. They were transferred into six airconditioned growth chambers, all receiving a basic illumination of $9 \mathrm{~h}$ daylight (from 8 A.M. to 5 P.M.) by a metal halogen lamp (Osram: HQI-T, $1000 \mathrm{~W})$. Photon flux density (400-700 nm) at plant level was 400 to $700 \mu \mathrm{mol} \mathrm{s}^{-1} \mathrm{~m}^{-2}$, corresponding to $95 \%$ of photosynthetic light saturation (Körner and Diemer, 1987). The basic illumination was prolonged to $12,14.5,15$, and $16 \mathrm{~h}$ (Fig. 1) of day length by weak incandescent light $\left(\sim 11 \mu \mathrm{mol} \mathrm{m} \mathrm{m}^{-2} \mathrm{~s}^{-1}\right)$ from two 40-W lightbulbs positioned $40 \mathrm{~cm}$ above the plants (Heide and Gauslaa, 1999). This combination of constant daylight with variable, weak, red-dominated light ensured that all experimental plants received a similar dose of photosynthetic active radiation. The photoperiodic effects observed were therefore not overshadowed by an increased overall light dose for photosynthesis. The 16-h photoperiod was chosen because the maximum astronomical day length at Mount Schrankogel is 15 h 54 min between 16 and 24 June, excluding dawn and dusk periods. Currently, this is also the period of snowmelt in our sampling area (according to data by Gottfried et al., 1999). If temperatures increase, snow may melt in mid-May, a month earlier, which corresponds to a 15$\mathrm{h}$ photoperiod, or even in mid-March, corresponding to a 12-h photoperiod. All photoperiod treatments were combined with an 11/ $6^{\circ} \mathrm{C}$ (day/night) temperature treatment. A subset of two chambers (one with 12 - and one with 16 -h photoperiod) was maintained at $18 / 8^{\circ} \mathrm{C}$ (Fig. 1). Temperatures oscillated by $\pm 2^{\circ} \mathrm{C}$ around the set temperatures. The warm/cold temperature treatment was intended not to simulate a certain warming scenario but to reveal a clear-cut indication of temperature versus photoperiod sensitivity while still retaining an ecologically relevant temperature range. Pots were randomized in the chambers twice per week and between the chambers (while retaining photoperiod) twice during the experiment to reduce potential chamber effects.

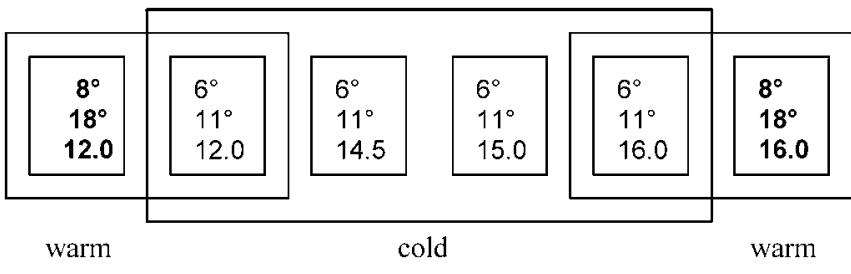

Nighttime temperature ${ }^{\circ} \mathrm{C}$

Daytime temperature ${ }^{\circ} \mathrm{C}$

Photoperiod (h)
FIGURE 1. Experimental design (treatment combinations in six growth cabinets). 


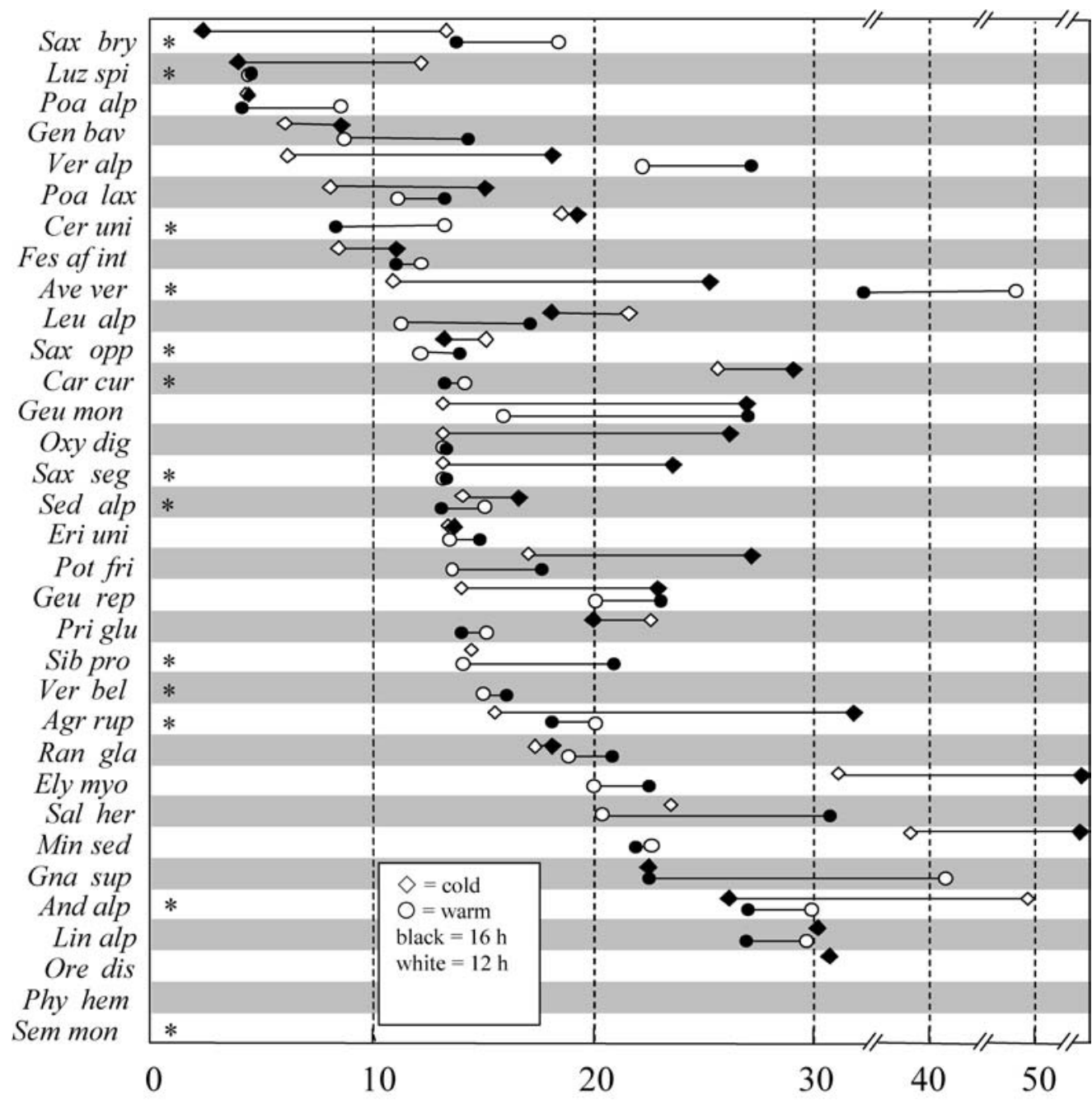

Number of days after release from the freezer
FIGURE 2. Influence of temperature and photoperiod on the number of days to emergence of new green leaves. Diamonds represent cold, circles warm treatments; white symbols stand for 12-h and black for 16-h photoperiods. Species with * had overwintered with green leaves.
After the end of the artificial 12-wk growth period, we collected 5-10 leaves per species for leaf area determination and subsequent drying at $60^{\circ} \mathrm{C}$ for $48 \mathrm{~h}$ for specific leaf area, $\mathrm{dm}^{2} \mathrm{~g}^{-1}$, determination. Leaves were measured on one side and pooled per species, permitting only across-species statistics.

\section{OBSERVATIONS AND DATA ANALYSIS}

All plants were inspected every second day. Apart from the beginning of flowering, we also noted the date at which each new green leaf emerged (Fig. 2). In retrospect, this allowed us to define the date at which $90 \%$ of all green leaves had emerged.

Since our primary aim was to identify influences of photoperiod on flowering, we first grouped the species by presence or absence of flowers under a given photoperiod treatment. In a second step, species were grouped by their sensitivity to temperature. Flowering in alpine species most often depends on buds preformed in the previous season, and we could not know whether our sampled individuals had any hidden flowering buds from the previous year. Hence, the use of several individuals is not a replication in the statistical sense but a way to increase the probability of the inclusion of potentially flowering individuals that had undergone primary induction, as shown by Heide (1989). Individuals that did not flower during our test season were not necessarily unresponsive to the growth conditions but may not have developed flower buds in the preceding season. On the other hand, a single flower on 1 out of 36 individuals throughout the experiment may have been an "erratic" occurrence that is not indicative of a species-specific photoperiod response. As a compromise, we took into account only those species that had more than one flowering individual throughout the experiment, irrespective of how many flowers these individuals produced. Therefore, we had to exclude Agrostis rupestris, Avenochloa disticha, Geum montanum, Oreochloa disticha, Phyteuma hemisphaerica, Primula glutinosa, Salix herbacea, Sempervivum montanum, Veronica alpina, and Veronica belloides from the analysis of flowering responses. However, we report leafing and specific leaf area for all test species.

It was important to consider flowering as a yes-or-no event and not as a numerical phenomenon. A presence or absence rating did not permit statistical analyses in a situation where absence must not be rated as "no response." For the same reason, we did not allow a gradual rating (more or less flowers). Once responsive species (in terms of flowering) were identified, we explored the parameter "days to flower" from the release of the freezer $(=0)$ to the flowering of each individual of the responsive species (mean per species and treatment). We assumed that the closer the photoperiod was to the species' optimum day length for flowering, the faster the flowers would open. Days to flower permitted a ranking of a plant's "preparedness" to flower. We distinguished four response classes: $<19,20-39,40-59$, and $>60 \mathrm{~d}$. Specific leaf area responses were compared across species by analysis of variance (ANOVA). 


\begin{tabular}{|c|c|c|c|c|}
\hline $\mathrm{PP}=$ & $12.00 \mathrm{~h}$ & $14.50 \mathrm{~h}$ & $15.00 \mathrm{~h}$ & $16.00 \mathrm{~h}$ \\
\hline flowering $\mathrm{sp}(\mathrm{n})$ & 11 & 17 & 18 & 20 \\
\hline$\%$ & 48 & 74 & 78 & 87 \\
\hline \multicolumn{5}{|l|}{ Cer uni } \\
\hline \multicolumn{5}{|l|}{ Ely myo } \\
\hline \multicolumn{5}{|l|}{ Min sed } \\
\hline \multicolumn{5}{|l|}{ Poa alp } \\
\hline \multicolumn{5}{|l|}{ Ran gla } \\
\hline \multicolumn{5}{|l|}{ Sax opp } \\
\hline \multicolumn{5}{|l|}{ Sax seg } \\
\hline \multicolumn{5}{|l|}{ And alp } \\
\hline \multicolumn{5}{|l|}{ Fes af int } \\
\hline \multicolumn{5}{|l|}{ Gna sup } \\
\hline \multicolumn{5}{|l|}{ Luz spi } \\
\hline \multicolumn{5}{|l|}{ Poa lax } \\
\hline \multicolumn{5}{|l|}{ Sax bry } \\
\hline \multicolumn{5}{|l|}{ Leu alp } \\
\hline \multicolumn{5}{|l|}{ Lin alp } \\
\hline \multicolumn{5}{|l|}{ Oxy dig } \\
\hline \multicolumn{5}{|l|}{ Sed alp } \\
\hline \multicolumn{5}{|l|}{ Eri uni } \\
\hline \multicolumn{5}{|l|}{ Pot fri } \\
\hline \multicolumn{5}{|l|}{ Sib pro } \\
\hline \multicolumn{5}{|l|}{ Geu rep } \\
\hline \multicolumn{5}{|l|}{ Gen bav } \\
\hline Car cur & & & & \\
\hline
\end{tabular}

$1=$ insensitive

$2=$ require $\mathrm{PP}$ of $14.50 \mathrm{~h}$ and longer

$3=$ require $\mathrm{PP}$ of $15 \mathrm{~h}$ and shorter

$4=$ no detectable pattern

FIGURE 3. Influence of photoperiod (PP) on flowering. Presence (dark areas) or absence (white areas) of flowers in the 12- $h, 14.5-h$, 15-h, and 16-h PPs in the cold treatments, and numbers and percentages of flowering species. Note: some species did not produce any flowers and are not shown (Agr rup, Ave vers, Geu mon, Leu alp, Phy hem, Pri glu, Sal her, Sem mon, Ver alp, Ver bel). For taxonomic abbreviations, see Table 1.

\section{Results}

\section{RESPONSE OF FLOWERING TO PHOTOPERIOD}

Twenty $(87 \%)$ of the investigated 23 species that produced flowers flowered at the 16 -h photoperiod in the cold (i.e., natural) temperature regime, whereas fewer species flowered at all shorter photoperiods (Fig. 3). Ten species of the 33 species sampled in the field had to be disregarded because only one (or no) individual flowered in the whole experiment. At the 12-h photoperiod, only 11 (48\%) species flowered.

As rated by the presence or absence of flowers, species fall into three reaction types (Fig. 3): (1) species insensitive to photoperiod (flowering occurred at any photoperiod: 7 species); (2) species

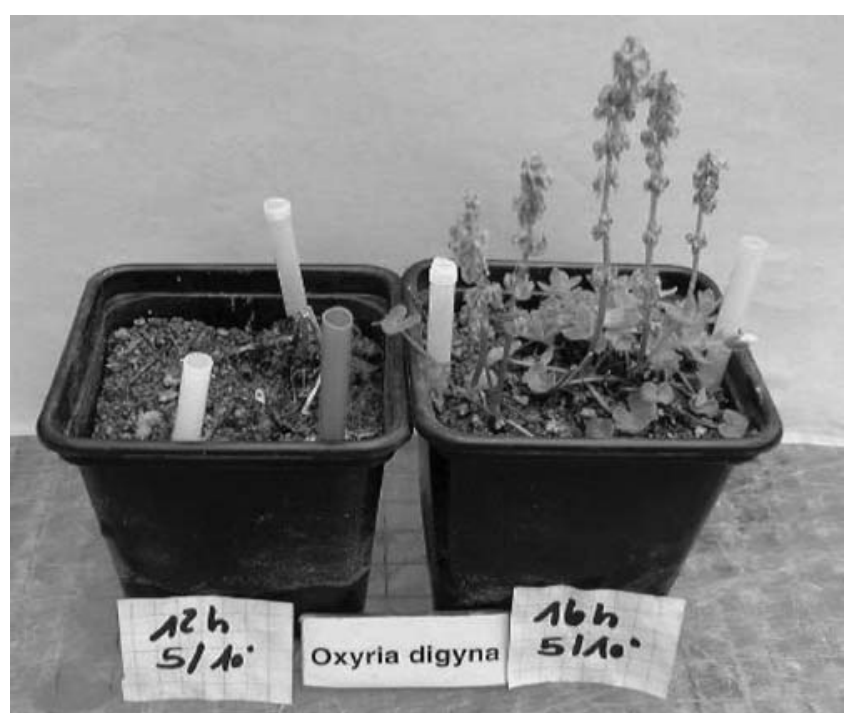

FIGURE 4. Photograph of the photoperiod-sensitive species Oxyria digyna $65 d$ after release from freezer in cold treatment for 12-h (left; life buds at the surface hardly visible) and 16-h photoperiods.

sensitive to photoperiod $>12 \mathrm{~h}$ (no flowers at $12 \mathrm{~h}$ but flowers at $14.5 \mathrm{~h}$ and longer: 10 species) (e.g., Oxyria digyna: Fig. 4); (3) species sensitive to photoperiod $<16 \mathrm{~h}$ (no flowers at $16 \mathrm{~h}$ but flowers at $15 \mathrm{~h}$ and shorter: 3 species); and (4) the remaining 3 species with no detectable pattern.

The majority of the investigated species in this analysis seemed to require longer photoperiods to flower, which resembles the actual conditions during flowering at the study site. Generally, the prolongation of the photoperiod (from $12 \mathrm{~h}$ to $16 \mathrm{~h}$ ) increased the number of species flowering (from 11 to 20).

\section{RESPONSE OF FLOWERING TO TEMPERATURE}

Surprisingly, the number of flowering individuals of these high alpine species did not consistently increase with increasing temperature in the range of our test. Three response types could be distinguished, irrespective of photoperiod (Fig. 5): (A) species insensitive to temperature, flowering at both cold and warm temperatures; (B) species requiring warm temperatures to flower; and (C) species flowering at cold temperatures only (an unexpected response).

Poa alpina produced true flowers only at 16-h photoperiod in the warm treatment. In all the other treatments (shorter day or cooler temperature or both), Poa alpina remained viviparous (result not shown in Fig. 5).

Most species were insensitive to an increase in temperature at equal photoperiod. By contrast, the change from the 16-h to the 12-h photoperiod strongly affected flowering in more than half of the species. Festuca af. intercedens flowered only under warm conditions when exposed to a 12-h photoperiod, whereas at the 16-h photoperiod it flowered under both cold and warm conditions (Fig. 5) because the warm temperature apparently compensated for the short photoperiod. In contrast, Potentilla frigida grown in the cold chambers flowered only at the 12-h photoperiod despite the fact that shoots grew (irrespective of photoperiod) more vigorously in the warm treatment (data not shown). The typical high-elevation species Cerastium uniflorum, Elyna myosuroides, Ranunculus glacialis, Saxifraga oppositifolia, and Saxifraga seguieri flowered soon after release from the freezer, irrespective of both photoperiod and temperature. 


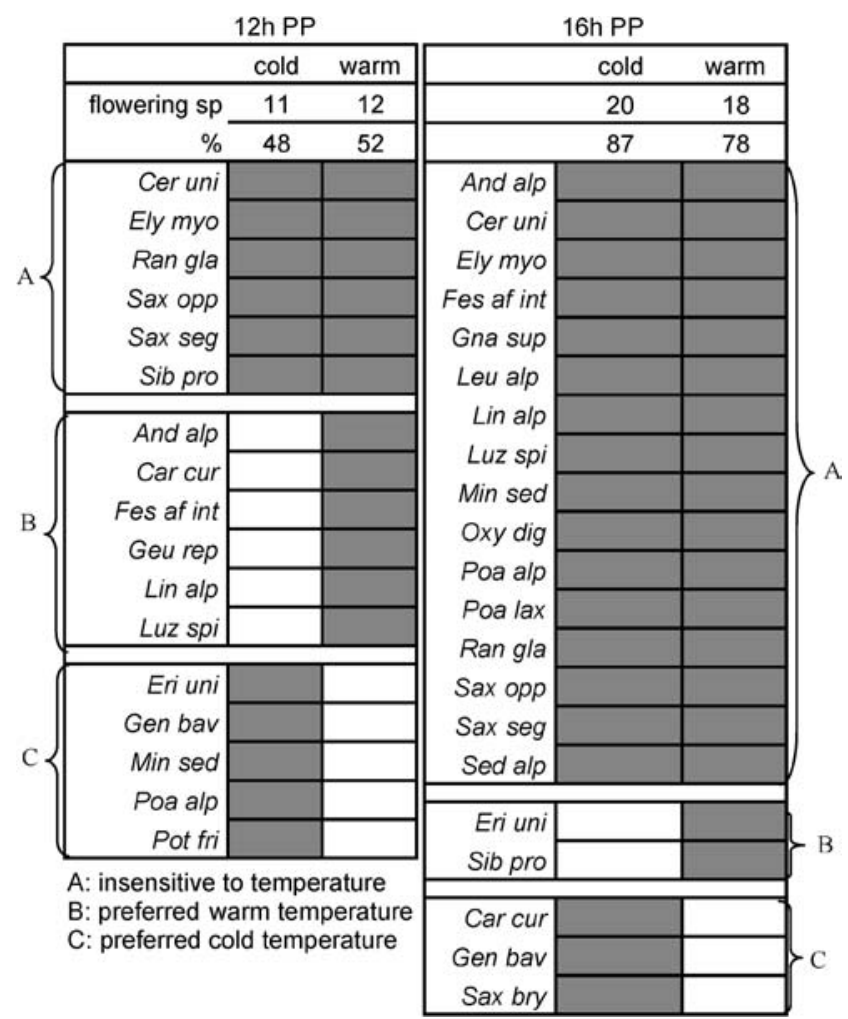

FIGURE 5. Influence of temperature on flowering. The presence (dark areas) or absence (white areas) of flowers in 12-h and 16-h photoperiods (PPs) and numbers and percentages of flowering species. Note: some species did not produce any flowers and are not shown (in 12- $h$ PP: Agr rup, Ave vers, Geu mon, Gnap sup, Leu alp, Ore dis, Oxy dig, Phy hem, Pri glu, Poa lax, Sal her, Sax bry, Sed alp, Ver alp, Ver bel; in 16-h PP: Geu mon, Geu rep, Sal her, Sem mon, Phy hem, Pri glu, Ver alp, Ver bel). For taxonomic abbreviations, see Table 1.

\section{NUMBER OF DAYS TO FLOWERING AT DIFFERENT PHOTOPERIODS}

In addition to the threshold response "yes-or-no flowering," photoperiod also had an effect on the number of days to flower. In general, flowers opened more rapidly at shorter photoperiods. In species that flowered under all conditions, the most rapid flowering occurred at the 12-h photoperiod in the warm treatment (Fig. 6). In this section, we use the response types defined in the preceding sections (Fig. 3).

Type 1 species required less time to flower as photoperiod became shorter (Ranunculus glacialis, Saxifraga seguieri, and Saxifraga oppositifolia), but the data were quite noisy. Saxifraga seguieri flowered most rapidly and required $14 \mathrm{~d}$ for its flowers to open in the 12-h photoperiod, whereas flowers of Elyna (=Kobresia) myosuroides required $45 \mathrm{~d}$ to open under the same conditions. Type 2 species did not show uniform responses in flowering speed. Type 3 species did not show any photoperiod sensitivity in flowering speed (Fig. 6).

\section{NUMBER OF DAYS TO FLOWERING AT DIFFERENT TEMPERATURES}

Although warming hardly affected the number of species flowering at a given photoperiod, it accelerated the speed of flower opening in most species (Fig. 7). In this section we use the types defined earlier (Fig. 5). In the 12-h photoperiod, speed of flowering was insensitive to temperature in the type A species Ranunculus
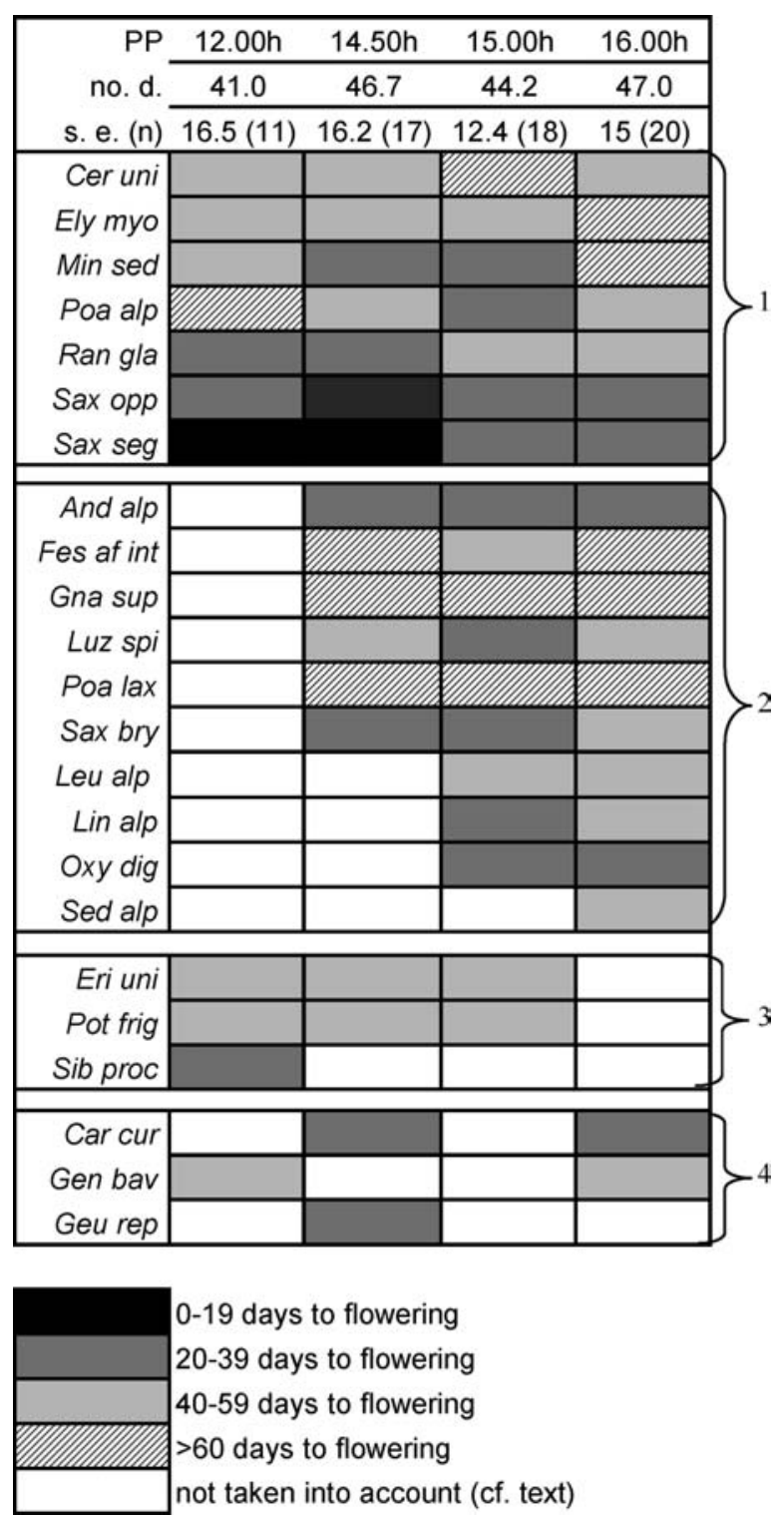

FIGURE 6. Influence of photoperiod (PP) on the number of days to flowering in the cold treatment (12-h, 14.5-h, 15-h, and 16-h PPs). Note: some species did not produce any flowers and are not shown (see Fig. 3).

glacialis, Saxifraga seguieri, and Sibbaldia procumbens (no data for type $\mathrm{B}$ and $\mathrm{C}$ species because they flowered either in warm or cold conditions only: Fig. 7). In the 16-h photoperiod, the type A species Androsacea alpina, Linaria alpina, and Oxyria digyna were the only temperature-insensitive species. All other type A species opened their flowers more rapidly at warmer temperatures (for types B and C, see earlier sections, Fig. 7). Saxifraga seguieri and Saxifraga oppositifolia, two opportunistic species, opened their flowers most rapidly.

In summary, flowering of $54 \%$ of the investigated species was sensitive to photoperiod. In a 12 -h photoperiod, $65 \%$ of the species flowered either in cold or in warm temperature only, and are therefore sensitive to temperature, whereas in a 16 -h photoperiod only $24 \%$ were temperature sensitive (Table 2). Speed of flowering was sensitive to photoperiod in $46 \%$ of all investigated species that flowered. At a 12-h photoperiod, number of days to flowering was sensitive to temperature in only $18 \%$ of the species, compared to $62 \%$ at a 16 -h photoperiod (Table 2). 


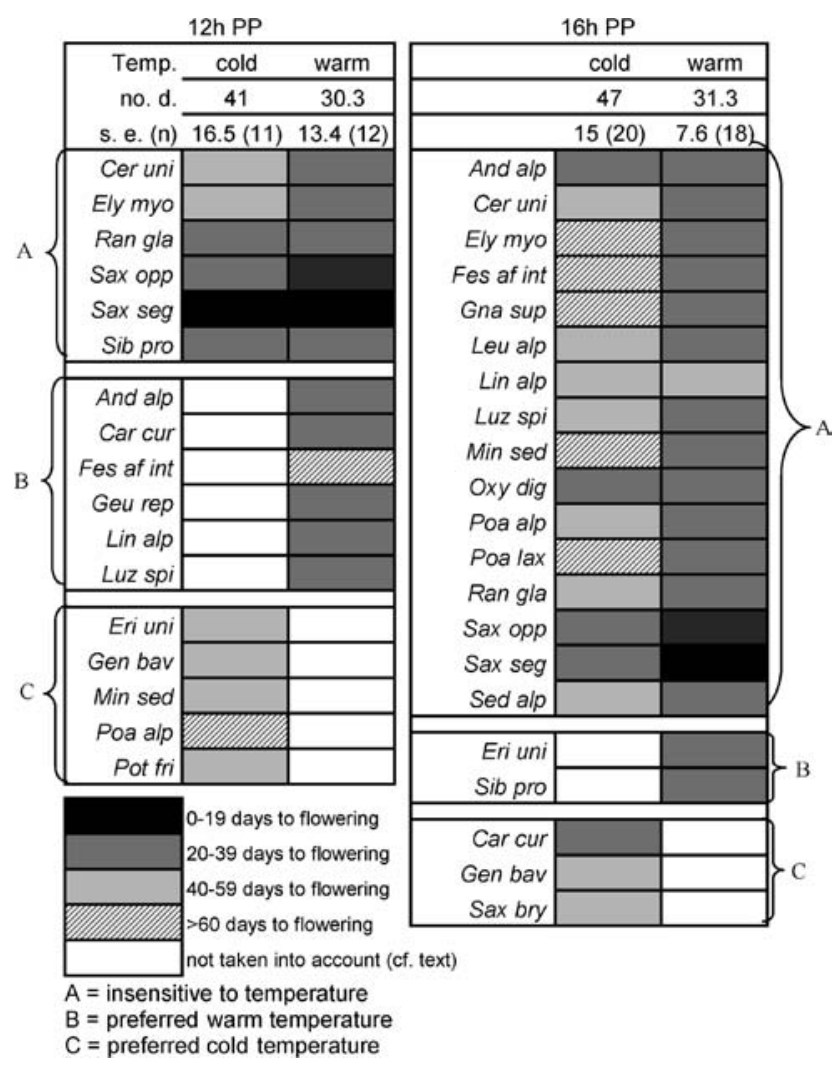

FIGURE 7. Influence of temperature on the number of days to flowering (12-h and 16-h photoperiods [PPs]). Note: some species did not produce any flowers and are not shown (see Fig. 5).

\section{RESULTS OF VEGETATIVE GROWTH}

Vegetative phenology was difficult to assess because some species had overwintered with green leaves (a common phenomenon in the field), and vegetative developmental stages were often hard to identify. We will limit the description of the vegetative growth to the duration of leafing and to a brief account of specific leaf area.

Irrespective of temperature, plants in the 12-h treatments continued producing new leaves for a shorter period of time than plants grown in the 16-h treatments, but interspecific variation was large; hence, the difference was statistically not significant (12-h photoperiod: $17.5 \pm 1.3 \mathrm{~d}, \mathrm{n}=2 \times 33$ for two temperature regimes; $16-\mathrm{h}$ photoperiod: $19.8 \pm 1.3 \mathrm{~d}, \mathrm{n}=2 \times 33$ for two temperature regimes).

Independently of photoperiod, the mean number of days until $90 \%$ of new green leaves had emerged was greater in the cold than in the warm treatments (marginally significant for $16-\mathrm{h}$ photoperiod at $P=0.075$ ). On average, species continued producing new leaves during more days in the cold treatments than they did in the warm treatments. The effect was small $(2 \mathrm{~d})$ in the 12 -h photoperiod and more pronounced $(5 \mathrm{~d})$ in the $16-\mathrm{h}$ photoperiod.

\section{SPECIFIC LEAF AREA}

Although the expected trend occurred with specific leaf area becoming larger at the $16-\mathrm{h}$ photoperiod compared to the 12-h photoperiod, irrespective of temperature (Fig. 8), the difference was not statistically significant for any individual species or for all species together (Table 3 ). For forbs alone, specific leaf area was marginally significantly higher at the 16 -h photoperiod $(P=0.077)$. Temperature effects on specific leaf area were not significant in grasses, but in forbs specific leaf area was significantly higher in the warm treatment, irrespective of photoperiod. The interaction between photoperiod and temperature was not significant.
TABLE 2

Influence of photoperiod $(P P)$ and temperature on number of species flowering and number of days to flowering of insensitive and sensitive species and species with no clear pattern ${ }^{\mathrm{a}}$

\begin{tabular}{|c|c|c|c|}
\hline \multicolumn{4}{|c|}{ Number of species flowering } \\
\hline $\begin{array}{c}\text { Treatment combination: PP } \\
\text { Temperature }\end{array}$ & $\begin{array}{c}12 \mathrm{~h}, 14.5 \mathrm{~h}, 15 \mathrm{~h}, 16 \mathrm{~h} \\
\text { cold }\end{array}$ & $\begin{array}{c}12 \mathrm{~h} \\
\text { cold vs warm }\end{array}$ & $\begin{array}{c}16 \mathrm{~h} \\
\text { cold vs warm }\end{array}$ \\
\hline number of sensitive species & $13(54)$ & $11(65)$ & $5(24)$ \\
\hline number of insensitive species & 7 (29) & $6(35)$ & $16(76)$ \\
\hline species with no clear pattern & $4(17)$ & 0 & 0 \\
\hline \multicolumn{4}{|c|}{ Number of days to flowering } \\
\hline Treatment combination: PP & $12 \mathrm{~h}, 14.5 \mathrm{~h}, 15 \mathrm{~h}, 16 \mathrm{~h}$ & $12 \mathrm{~h}$ & $16 \mathrm{~h}$ \\
\hline Temperature & cold & cold vs warm & cold vs warm \\
\hline number of sensitive species & $11(46)$ & $3(18)$ & $13(62)$ \\
\hline number of insensitive species & $9(38)$ & $3(18)$ & $3(14)$ \\
\hline species with no clear pattern & $4(17)$ & $11(64)$ & $5(24)$ \\
\hline
\end{tabular}

${ }^{a}$ Numbers in parentheses $=\%$ of all flowering species in this treatment combination.

Note: sum of species varies, because flowering did not occur in the same number of species in all treatment combination.

\section{Discussion}

Photoperiod affects reproductive phenology in about half of the 23 alpine species included in this test. Nine species were sensitive to both photoperiod and temperature. Three typical alpine pioneer species, Ranunculus glacialis, Saxifraga oppositifolia, and Saxifraga seguieri and also Cerastium uniflorum and Elyna (= Kobresia) myosuroides were insensitive to both photoperiod and temperature in flower development. Hence, these species flowered shortly after release from dormancy (snow cover) irrespective of the climate they experienced. Vegetative development, represented by the duration of new leaf production, was slightly prolonged in long days, independent of temperature. The effects of both photoperiod and temperature on specific leaf area were weak for all 33 species taken together. Remarkably, the responses to both photoperiod and temperature were significant in forbs (larger specific leaf area in the 16-h photoperiod and in the warm treatment) but not in graminoids, explaining the nonsignificant response across all species.

If we compare the results of our experiment with the actual photoperiod at the onset of flowering and peak of flowering in the region from which we sampled our experimental plants (data from Mount Glungezer, $47^{\circ} 13^{\prime} \mathrm{N} ; 11^{\circ} 31^{\prime} \mathrm{E}$ : Bahn and Körner, 1987), it becomes evident that most of the species are currently flowering around the longest day of the year, i.e., close to our 16-h photoperiod, at which 20 of the 23 species flowered. The species of type 2 (Fig. 3), requiring a photoperiod of $14.5 \mathrm{~h}$ and longer, fit the findings of Bahn and Körner (1987) as well. The authors separated these species even further into those that flower closer to a 16-h photoperiod (Androsacea alpina, Luzula spicata, Linaria alpina, Oxyria digyna, and Leucanthemopsis alpina) and those that flower around $15 \mathrm{~h}$ (Gnaphalium supinum, Poa laxa, Saxifraga bryoides, and Sedum alpestre), which goes beyond the scope of our study. Of our type 3 species, which require photoperiods of $15 \mathrm{~h}$ and shorter, Bahn and Körner's list included only Erigeron uniflorum. Indeed, this species has its mean flowering peak at a photoperiod of $14 \mathrm{~h} 52 \mathrm{~min}$ and starts flowering at a photoperiod of $15 \mathrm{~h} 21 \mathrm{~min}$. Hence, our experimental findings match these field observations.

There are very few studies on photoperiodism in alpine species that permit comparison with our findings. Arctic Oxyria digyna flowered and grew new leaves in a $24-\mathrm{h}$ photoperiod at $18^{\circ} \mathrm{C}$ after 


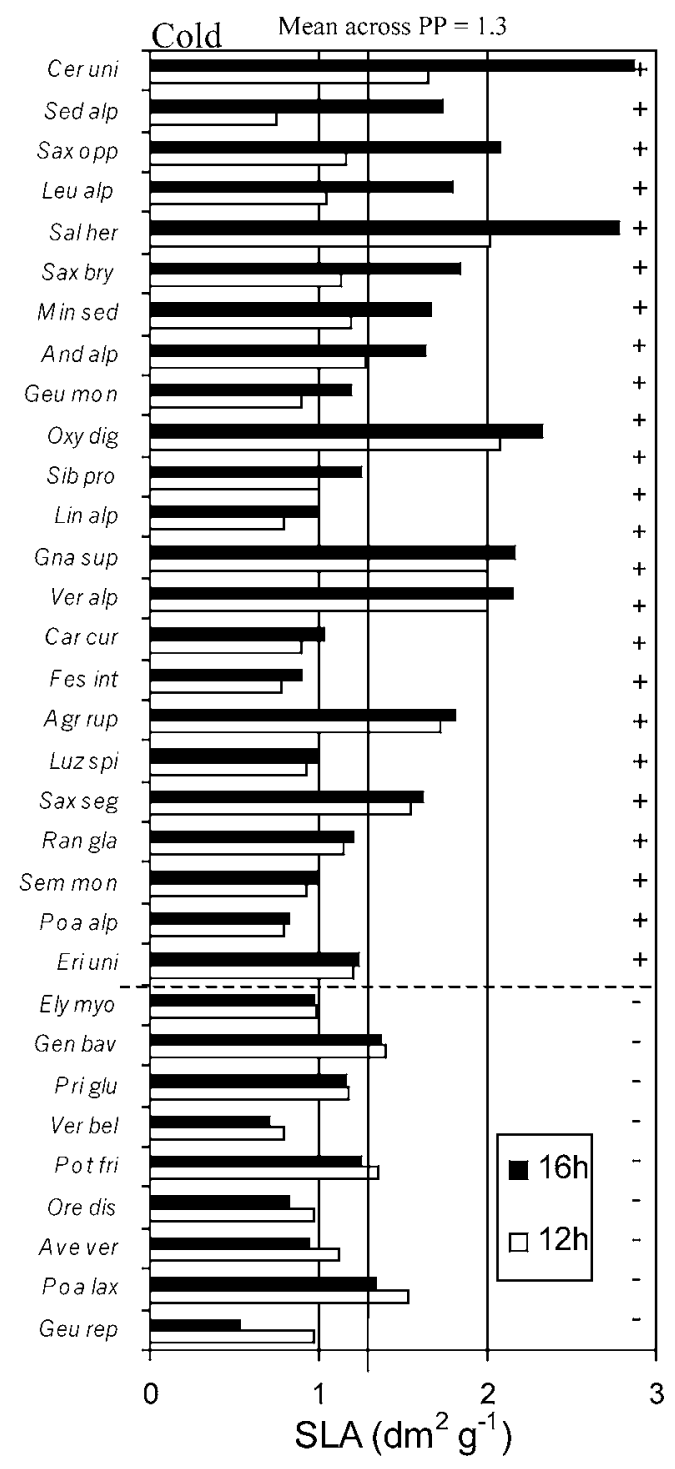

having experienced a short-day primary induction regardless of previous temperature conditions (Heide, 2001). Individuals exposed to a 10-h photoperiod remained dormant irrespective of temperature. Heide's (2001) estimated critical photoperiod (for Scandinavia) was about $15 \mathrm{~h}$ for flowering, which is in line with our findings (for the Alps). Our observation that vivipary in Poa alpina depends on both photoperiod and temperature confirmed Heide's (1989) findings that flowering occurred only at photoperiods of $15 \mathrm{~h}$ and longer, and at warmer temperatures. As with Poa bulbosa and Festuca vivipara, short days and low temperatures induced viviparous proliferation in $\mathrm{Poa}$ alpina, suggesting that vivipary is acclimative, i.e., phenotypic and not genotypic. The marked requirement for long photoperiod and warm temperatures for flowering of Oxyria digyna and Sedum alpestre also agrees with the results for Sedum telephium by Heide (2001).

The results of this broad screening for photoperiod sensitivity in alpine taxa suggest that a change in the timing of snowmelt (photoperiod at emergence) will cause differing responses among species and thus induce biodiversity effects. Our results correspond with work by Heide (1989) and Prock and Körner (1996) showing that these photoperiod responses are most likely ecotypic (i.e., reflect an evolutionary adaptation to the prevailing local photoperiod). These differing photoperiod controls constrain predictions of a species' future success based on temperature scenarios alone.

The current snowmelt on Mount Schrankogel, where we collected

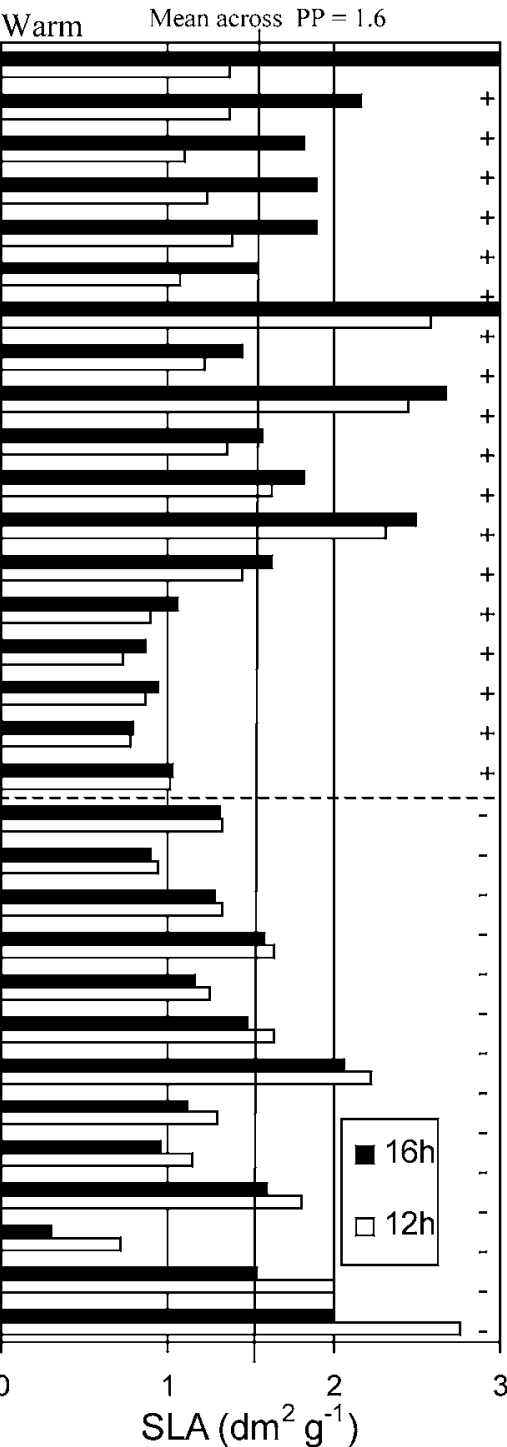

FIGURE 8. The influence of photoperiod and temperature on specific leaf area (SLA), sorted by the magnitude of the 16-h vs. 12-h photoperiod (PP) differences in SLA. our plants, occurs between mid-June and the end of June at a photoperiod of about $16 \mathrm{~h}$ (Gottfried et al., 1999). A 1-mo-earlier snowmelt would correspond to a $15-\mathrm{h}$ photoperiod, which, according to our data, would exert little influence on phenology because most photoperiod-sensitive species react when the photoperiod becomes shorter than $15 \mathrm{~h}$. However, if snow melted $6 \mathrm{wk}$ earlier, at the beginning of May (photoperiod $=14.5 \mathrm{~h}$ ), a substantial number of species would have difficulty flowering. Linaria alpina, Oxyria digyna, Sedum alpestre, and Leucanthemopsis alpina, which require longer photoperiod, would experience a prolonged dormant or vegetative phase before they flowered. It is possible that these late-snowmelt specialists perceive a short photoperiod as a signal that the season has progressed beyond midsummer. Erigeron uniflorum, Potentilla frigida, and Sibbaldia procumbens, which developed faster in shorter photoperiods, may benefit from an earlier snowmelt.

Given the predictions and the recent evidence of enhanced latewinter snowfalls (IPCC, 2001), climatic change may lead not only to warmer temperatures but also to increased snowpack at high elevations (>2000 m a.s.1.). A snowmelt delayed until late July, as happened in 1999 (i.e., after the longest photoperiod has passed), would inhibit flowering for species that require longer photoperiods.

For obvious practical reasons we have set photoperiods to a certain fixed duration (see Heide, 1990). Our conclusions rest on the traditional assumption of a genetic photoperiod threshold; hence the 
TABLE 3

Influence of photoperiod $(P P)$ and temperature $(T)$ on mean specific leaf area (SLA) and statistical significance

\begin{tabular}{lccc}
\hline \hline & & \multicolumn{2}{c}{ SLA } \\
\cline { 3 - 4 } Funct. Groups & PP & cold & warm \\
\hline Grasses $(\mathrm{n}=9)$ & 12 & $1.08 \pm 0.14$ & $1.09 \pm 0.14$ \\
Forbs $(\mathrm{n}=23)$ & 12 & $1.21 \pm 0.10$ & $1.59 \pm 0.11$ \\
All $(\mathrm{n}=32)$ & 12 & $1.07 \pm 0.14$ & $1.33 \pm 0.10$ \\
Grasses $(\mathrm{n}=9)$ & 16 & $1.56 \pm 0.11$ & $1.69 \pm 0.11$ \\
Forbs $(\mathrm{n}=23)$ & 16 & $1.39 \pm 0.10$ & $1.59 \pm 0.10$ \\
All $(\mathrm{n}=32)$ & 16 & Temperature & $\mathrm{PP} \times \mathrm{T}$ \\
\multicolumn{1}{c}{ ANOVA: } & $\mathrm{PP}$ & 0.398 & 0.355 \\
gasses & 0.422 & $0.043^{*}$ & 0.345 \\
forbs & $0.077(*)$ & $0.024^{*}$ & 0.824 \\
all species & 0.107 & &
\end{tabular}

* significant effects.

predefined, fixed photoperiod treatment. In the real world, plants would experience a dynamic change of photoperiod. We cannot exclude the possibility that some of the inhibitory short-day effects would be moderated before 21 June in a dynamic photoperiod. However, in case of prolonged snow cover and a shift of the beginning of the season beyond the end of June, the progressive shortening of days could enhance effects seen here at a fixed photoperiod. However, the overall differentiation among species would most likely stay the same.

\section{Conclusions}

This study revealed substantial developmental consequences of plant emergence from snow at contrasting photoperiods in flowering. Photoperiod indeed affects flowering in about half of the alpine taxa we examined. It was possible to identify species that are insensitive to photoperiod, those that require a longer photoperiod, and those that require a shorter photoperiod. Effects of temperature were less pronounced. Vegetative responses pointed in the same direction but were less pronounced. The different response of specific leaf area in graminoids and forbs underlined other possible biodiversity effects of photoperiod.

A likely consequence of all these species-specific responses to a warmer climate and assumed earlier snowmelt is a rearrangement of community composition. Any attempts at predicting or modeling future alpine plant distribution based on warming scenarios needs to account for photoperiod constraints. Warming may be too rapid to track the change in photoperiod by evolutionary adjustment in many of these slowly reproducing species.

\section{Acknowledgments}

This article is part of a Ph.D. thesis under the supervision of M. Beniston (Fribourg, Switzerland). The authors thank E. Graham for linguistic help and S. Pelaez-Riedl and L. Zimmermann for technical assistance during the experimental work in Basel. Special thanks are due to O. Heide for commenting on an earlier draft and to G. Grabherr and coworkers, in particular M. Gottfried and H. Pauli, for their cooperation and support in the field.

\section{References Cited}

Bahn, M., and Körner, C., 1987: Vegetation und Phänologie der hochalpinen Gipfelflur des Glungezer in Tirol. Ber. nat.-med. Verein Innsbruck, 74: 61-80.
Barry, R. G., 1992: Mountain Weather and Climate. London:, Routledge. 432 pp.

Beniston, M., 2000: Environmental Change in Mountains and Uplands. London: Arnold/Hodder, Stoughton/Chapman, and Hall Publishing Company. 172 pp.

Bernier, G. K. J., and Sachs, R. M., 1981: The Physiology of Flowering, Vol. 1. Boca Raton, FL: CRC Press. 149 pp.

Braun-Blanquet, J., 1957: Ein Jahrhundert Florenwandel am Piz Linard (3414 m). Bulletin du Jardin Botanique Etat Bruxelles, Volume jubilaire Walter Robyns: 221-232.

Ehrendorfer, F., 1973: Liste der Gefässpflanzen Mitteleuropas. Stuttgart: Gustav-Fischer-Verlag. 318 pp.

Gottfried, M., Pauli, H., and Grabherr, G., 1998: Prediction of vegetation patterns at the limits of plant life: a new view of the alpine-nival ecotone. Arctic and Alpine Research, 30: 207-221.

Gottfried, M., Pauli, H., Reiter, K., and Grabherr, G., 1999: A finescaled predictive model for changes in species distribution patterns of high mountain plants induced by climate warming. Diversity and Distribution, 5: 241-251.

Grabherr, G., Gottfried, M., and Pauli, H., 1994: Climate effects on mountain plants. Nature, 369: 448.

Heide, O., 1985: Physiological aspects of climatic adaptation in plants with special reference to high-latitude environments. In Kaurin, A., Juntilla, O., and Nilsen, J. (eds.), Plant Production in the North. Proceedings of the Plant Adaptation Workshop, Troms $\varnothing$, Norway, 4-9 September 1983, 1-22.

Heide, O., 1989: Environmental control of flowering and viviparous proliferation in seminiferous and viviparous arctic populations of two Poa species. Arctic and Alpine Research, 21: 305-315.

Heide, O., 1990: Dual floral induction requirements in Phleum alpinum. Annals of Botany, 66: 678-694.

Heide, O., 2001: Photoperiodic control of dormancy in Sedum telephium and some other herbaceous perennial plants. Physiologia Plantarum, 113: 332-338.

Heide, O., Pedersen, K., and Dahl, E., 1990: Environmental control of flowering and morphology in the high-arctic Cerastium regelii, and the taxonomic status of C. jenisejense. Nordic Journal of Botany, 10: 141-147.

Heide, O., and Gauslaa, Y., 1999: Development strategies of Koenigia Islandica, a high-arctic annual plant. Ecography, 22: 637-642.

Hofer, H. R., 1992: Veränderungen in der Vegetation von 14 Gipfeln des Berninagebietes zwischen 1905 und 1985. Ber. Geobot. Inst. ETH. Stiftung Rübel Zürich, 58: 39-54.

IPCC (Intergovernmental Panel on Climate Change), 2001: Climate Change 2001-The Third Assessment report of the Intergovernmental Panel on Climate Change, 2: Impacts, Adaptations, and Vulnerability. Contribution of working group II. Cambridge: University Press. 1023 pp.

Körner, Ch., 1999: Alpine Plant Life. Springer, Berlin, Heidelberg. 338 pp.

Körner, Ch., and Diemer, M., 1987: In situ photosynthetic responses to light, temperature and carbon dioxide in herbaceous plants from low and high altitude. Functional Ecology, 1: 179194.

Larcher, W., 1994: Oekophysiologie der Pflanzen: Leben, Leistung und Stressbewältigung der Pflanze in ihrer Umwelt. Stuttgart: Ulmer. 394 pp.

Menzel, A., and Fabian, P., 1999: Growing season extended in Europe. Nature, 397: 659.

Myneni, R. B., Keeling, C., Tucker, C. J., Asarar, G, and Nemani R. R., 1997: Increased plant growth in the northern latitudes from 1981 to 1991. Nature, 386: 698-701.

Prock, S., and Körner, Ch., 1996: A cross-continental comparison of phenology, leaf dynamics and dry matter allocation in arctic and temperate zone herbaceous plants form contrasting altitudes. Ecological Bulletins, 45: 93-103.

Ms submitted February 2002 Revised ms submitted September 2002 